DOI: $10.15593 / 2224-9982 / 2018.52 .06$

УДК: 669.715.018.28-153.71:629.7

\author{
В.Г. Долгополов ${ }^{1}$, В.А. Дубровский ${ }^{2}$, М.Ю. Симонов ${ }^{1}$, \\ Ю.Н. Симонов ${ }^{1}$, М.А. Медведева ${ }^{1}$ \\ ${ }^{1}$ Пермский национальный исследовательский политехнический университет, Пермь, Россия \\ ${ }^{2}$ ПАО «Протон-ПМ», Пермь, Россия

\section{СТРУКТУРНЫЕ ОСОБЕННОСТИ ГОМОГЕНИЗИРОВАННОГО СИЛУМИНА, ИСПОЛЬЗУЕМОГО В АВИАКОСМИЧЕСКОЙ ОТРАСЛИ, С МОДИФИЦИРОВАНИЕМ И БЕЗ НЕГО}

\begin{abstract}
Изучено влияние перегрева жидкого сплава силумина, а также влияние модифицирования на его структуру. Для получения сплавов использовали вакуумно-индукционную тигельную печь. Исследуемый в работе сплав широко применяется при изготовлении корпусных деталей и крыльчаток в ракетостроении.

Исследовано микростроение гомогенизированного силумина с дополнительным модифицированием и без него, показано, что введение модификатора приводит к измельчению всех компонентов структуры, а также эвтектики, установлено, что введение модификатора приводит к уменьшению размеров иероглифических компонентов структуры. Проведены исследования расположения структурных элементов и некоторых химических элементов на поверхности разрушения у цилиндрических образцов (5 мм), испытанных на одноосное растяжение.

Помимо традиционных структурных составляющих металлографический анализ показал наличие светлых частиц и пластин, расположенных по границам структурных элементов. Светлые пластины расположены хаотично по всему объему расплава. Выявлено, что модифицирование сдерживает рост зерен, а также рост, коагуляцию и расположение по объему микроструктуры светлых частиц. Исследование элементного состава светлых частиц, а также светлых пластин показало, что в состав этих частиц и пластин входит цирконий со средним содержанием порядка $30 \%$.

Металлографический анализ проводили на микрошлифах при увеличениях от $\times 500$ до $\times 8000$ и ускоряющем напряжении 15 кB на сканирующем электронном микроскопе FEI PHENOM G2 ProX. Элементный анализ проводили на энергодисперсионном спектрометре электронного микроскопа с разрешением $120 \mathrm{eV}$ при ускоряющем напряжении 15 кВ. Общее количество полей сбора информации при элементном анализе состава фаз для каждого сплава составлял не менее 20.

Ключевые слова: алюминиевые сплавы, силумин, гомогенизирующая обработка, структура, эвтектика, модифицирование, пластины циркония, зерно, жидкий расплав, коагуляция, диспергирование.
\end{abstract}

\author{
V.G. Dolgopolov ${ }^{1}$, V.A. Dubrovskiy ${ }^{2}$, M.Yu. Simonov ${ }^{1}$, \\ Yu.N. Simonov', M.A. Medvedeva ${ }^{1}$ \\ ${ }^{1}$ Perm National Research Polytechnic University, Perm, Russian Federation \\ ${ }^{2}$ PAO «Proton-PM», Perm, Russian Federation
}

\title{
THE METHODSOF INFLUENCE ON THE STRUCTURE AND PROPERTIES OF ALUMINUM ALLOYS USED IN THE AEROSPACE INDUSTRY
}

\footnotetext{
The effect of superheating of a silumin alloy liquid, as well as the effect of modification on its structure, has been studied. To produce alloys, a vacuum-induction crucible furnace was used.

The microstructure of a homogenized silumin with additional modification without it has been studied, it is shown that the introduction of a modifier leads to a grinding of all components of the structure as well as a eutectic, it is established that the introduction of a modifier leads to a decrease in the size of the hieroglyphic components of the structure. The location of structural elements and some chemical elements on the fracture surface in cylindrical samples $(5 \mathrm{~mm})$ tested for uniaxial tension was studied.

In addition to the traditional structural components, metallographic analysis showed the presence of light particles and plates located along the boundaries of structural elements. Light plates are located randomly throughout the melt volume. It was found that modifying inhibits the growth of grains, as well as growth, coagulation and arrangement of the volume of microstructure of light particles. The study of the elemental composition of light particles, as well as of light plates, revealed that zirconium with an average content of about $30 \%$ is part of these particles and plates.
} 
The metallographic analysis was carried out on microsections at magnifications from $\times 500$ to $\times 8000$ and an accelerating voltage of $15 \mathrm{kV}$ on a scanning electron microscope FEI PHENOM G2 ProX. Elemental analysis was performed on an energydispersive electron microscope spectrometer with a resolution of $120 \mathrm{eV}$ at an accelerating voltage of $15 \mathrm{kV}$. The total number of fields for collecting information for an elemental analysis of the phase composition for each alloy was at least 20.

Keywords: aluminum alloys, silumin, homogenizing treatment, structure, eutectic modifying the mechanical properties, grain, liquid melt microscopic mechanism of crack growth.

\section{Введение}

Важнейшей задачей для России в XXI в. является освоение околоземного пространства и ближнего космоса. Для этого потребуются ракетоносители тяжелого и сверхтяжелого класса. Одной из важнейших проблем использования данных ракетных аппаратов является снижение стартовой массы изделия в сборке до минимально возможного для увеличения полезной нагрузки. Снижение массы изделия, как правило, сопряжено с использованием новых, более легких и прочных материалов или улучшением свойств уже используемых сплавов. В ракетной отрасли, в сегменте получения крупногабаритных отливок сложной конфигурации, широкое распространение получили силумины - сплавы на основе систем Al-Si [1]. Данные сплавы обладают хорошими литейными свойствами, удовлетворительной обрабатываемостью резанием, свариваемостью и коррозионной стойкостью, для повышения которой детали анодируют и защищают лакокрасочными покрытиями. Например, сплав АК12 (АЛ2) используют для изготовления мелких, а АК9ч (АЛ4) и АК7ч (АЛ9) - средних и крупных деталей (корпусов компрессоров, картеров двигателей внутреннего сгорания) [2-4].

Недостатком литой структуры немодифицированных силуминов является грубое игольчатое строение, которое представляет собой конгломераты или отдельные дендриты эвтектики $(\alpha+\mathrm{Si})$, выделяющиеся из $\alpha$-твердого раствора алюминия в процессе кристаллизации [5]. Этот недостаток частично устраняется введением в расплав перед заливкой специально подобранных элементов - модификаторов [6].

Модификаторами I группы являются Ti, V и другие образующие тугоплавкие интерметаллиды $\mathrm{TiAl}_{3}$ и $\mathrm{VAl}_{6}$, а также ультрадисперсные частицы оксидов, карбидов, боридов и других неметаллических включений. Введение подобных присадок в литейные алюминиевые сплавы позволяет диспергировать отдельные дендриты $(\alpha+\mathrm{Si})$ в эвтектике за счет увеличения центров кристаллизации. Модификаторами II группы являются: $\mathrm{Li}, \mathrm{Na}, \mathrm{K}, \mathrm{Rb}, \mathrm{Cs}$, а также $\mathrm{S}$ и $\mathrm{P}$ и другие, введение подобных присадок позволяет диспергировать структуру за счет сдерживания роста кристаллов в процессе кристаллизации расплава вследствие выделения частиц циркония по границам зерен. В то же время отдельными авторами показана высокая эффективность комплексных модификаторов [7].

Цель работы: изучение особенностей фазового и элементного состава гомогенизированного алюминиевого сплава АК9ч с модифицированием и без него.

\section{Материалы и методики эксперимента}

В качестве материала исследования выбран доэвтектический силумин АК9ч (АЛ4), а также сплав АК9чМ* после модифицирования, химический состав которых представлен в табл. 1.

Таблица 1

Химический состав исследуемых сплавов

\begin{tabular}{|c|c|c|c|c|c|c|c|c|c|c|c|c|}
\hline Сплав, & \multicolumn{10}{c|}{ Содержание элементов, мас.\% } \\
\cline { 2 - 14 } \\
марка & $\mathrm{Al}$ & $\mathrm{Si}$ & $\mathrm{Mg}$ & $\mathrm{Mn}$ & $\mathrm{Cu}$ & $\mathrm{Fe}$ & $\mathrm{Ti}+\mathrm{Zr}$ & $\mathrm{Zn}$ & $\mathrm{Ni}$ & $\mathrm{Pb}$ & $\mathrm{Sn}$ & $\mathrm{Be}$ \\
\hline АК9ч & осн. & 9,51 & 0,26 & 0,25 & $<0,02$ & 0,21 & 0,1 & 0,01 & 0,03 & 0,009 & $<0,0065$ & $<0,0005$ \\
\hline AК9чM $^{*}$ & осн. & 9,79 & 0,12 & 0,26 & $<0,02$ & 0,21 & 0,1 & 0,01 & 0,04 & 0,009 & $<0,0065$ & $<0,0005$ \\
\hline
\end{tabular}

$\mathrm{M}^{*}$ - сплав АК9ч, подвергнутый модифицированию специальными компонентами. 
Базовый режим обработки расплава (АК9ч) заключался в расплавлении металла при температуре $1100{ }^{\circ} \mathrm{C}$ с выдержкой при данной температуре в течение 20 мин, далее расплав охлаждали до температуры заливки $750{ }^{\circ} \mathrm{C}$. Заливку образцов производили в песчаную форму.

При обработке по второму варианту (АК9ч $\mathrm{M}^{*}$ ), помимо базового режима обработки, в расплав после охлаждения до $750{ }^{\circ} \mathrm{C}$ вводили двойной модификатор.

Термическую обработку сплава производили по технической документации ПАО «Протон-ПМ».

Металлографический анализ проводили на микрошлифах при увеличениях от $\times 500$ до $\times 8000$ на сканирующем электронном микроскопе FEI PHENOM G2 ProX. Элементный анализ проводили на энергодисперсионном спектрометре электронного микроскопа с разрешением $120 \mathrm{eV}$ при ускоряющем напряжении 15 кВ. Общее количество полей сбора информации при элементном анализе состава фаз для каждого сплава составляло не менее 20 . В сводную таблицу данных количественного элементного анализа заносили результаты 7 измерений, случайным образом отобранные с помощью программы Randomize из всего массива данных; таким образом, в сводную таблицу занесено 35 \% всех измерений.

\section{Результаты и их обсуждение}

Металлографический анализ сплава АК9ч с помощью SEM показал присутствие иглопободных и иероглифоподобных элементов в твердом растворе $\alpha$-фазы алюминия (рис. $1, a$ ). Авторы работ [8-10] приводят фазовый состав игольчатых стуктурных элементов с молекулярной формулой $\mathrm{Al}_{5} \mathrm{FeSi}$, однако по данным [8] игольчатые структурные элементы совместно с матричным материалом могут также иметь фазовый состав Al-Si. По данным литературы [8-10] иероглифоподобные элементы структуры чаще всего являются четверными эвтектиками с молекулярными формулами $\left(\mathrm{Al}_{15}(\mathrm{Fe}, \mathrm{Mn})_{3} \mathrm{Si}_{2}\right)$ или $\left(\mathrm{Al}_{8} \mathrm{FeMg}_{3} \mathrm{Si}_{5}\right)$. В связи с тем, что существуют различные данные об элементном и фазовом составе сплава АК9ч, нами принято решение о проведении исследований количественного содержания элементов в фазах выплавленного сплава АК9ч.

Анализ микроструктуры АК9чМ* также показал наличие иероглифоподобных эвтектик со схожей скелетообразной морфологией (рис. $2, a$ ), однако по сравнению со сплавом АК9ч развитость скелетообразных эвтектик заметно меньше. Важно отметить, что в сплаве АК9чМ* произошло диспергирование структуры с изменением формы выделившейся эвтектики с игольчатой на глобулярную, с меньшими размерами: 8-12 мкм вместо 20-30 мкм.

На рис. 1-2 представлены области сбора информации элементного состава фаз и результаты проведения энергодисперсионного спектрального анализа в виде спектрограмм и табличных данных. Анализ результатов свидетельствует о том, что в твердом растворе $\alpha$-фазы алюминия присутствует кремний и серебро.

Совместный анализ компонентов структуры сплава АК9ч и Ак9чМ* показал схожий элементный состав у структурных компонентов.

1. В составе матрицы сплавов АК9ч и АК9чМ* наблюдается присутствие кремния ( $\mathrm{Si}$ ) и серебра (Ag) в количестве порядка 3,9-6,2 \% и 3,7-4 \% соответственно, основным элементом является алюминий в количестве 89,3-92\%.

2. В составе игольчатой структуры сплавов АК9ч и АК9чМ* присутствуют алюминий (Al) в количестве 6,1-19,2 \% и сурьма $(\mathrm{Sn})$ в количестве 1,2-3,5\%, основным элементом является кремний $(\mathrm{Si})$ в количестве 87-91\%. Игольчатая структура предположительно является $\beta$-фазой кремния $(\mathrm{Si})$ и совместно с областью матрицы является эвтектикой $\mathrm{Al}-\mathrm{Si}$.

3. В составе четверной эвтектики сплавов АК9ч и АК9чМ*, имеющей иероглифоподобную морфологию, зафиксировали присутствие алюминия $(\mathrm{Al})$, марганца $(\mathrm{Mn})$, железа $(\mathrm{Fe})$, кремния (Si) в количестве 64,4-71,9\%, 5,7-9,2\%, 4,8-9,2\%, 7,1-15,9\% соответственно, также отмечали спорадическое присутствие магния $(\mathrm{Mg})$ и меди $(\mathrm{Cu})$ в количестве $0,6-1,2 \%$ 
и $0,4-1,3 \%$. Молекулярная формула четверной эвтектики зависит от химического состава сплава. В данном сплаве во всех иероглифоподобных эвтектиках присутствовали железо и марганец, а магний и медь присутствовали в составе эвтектик спорадически, в связи с чем можно сделать вывод, что молекулярная формула иероглифоподобных четверных эвтектик в сплавах АК9ч и АК9чМ* имеет вид, близкий к $\left(\mathrm{Al}_{15}(\mathrm{Fe}, \mathrm{Mn})_{3} \mathrm{Si}_{2}\right)$ [8].
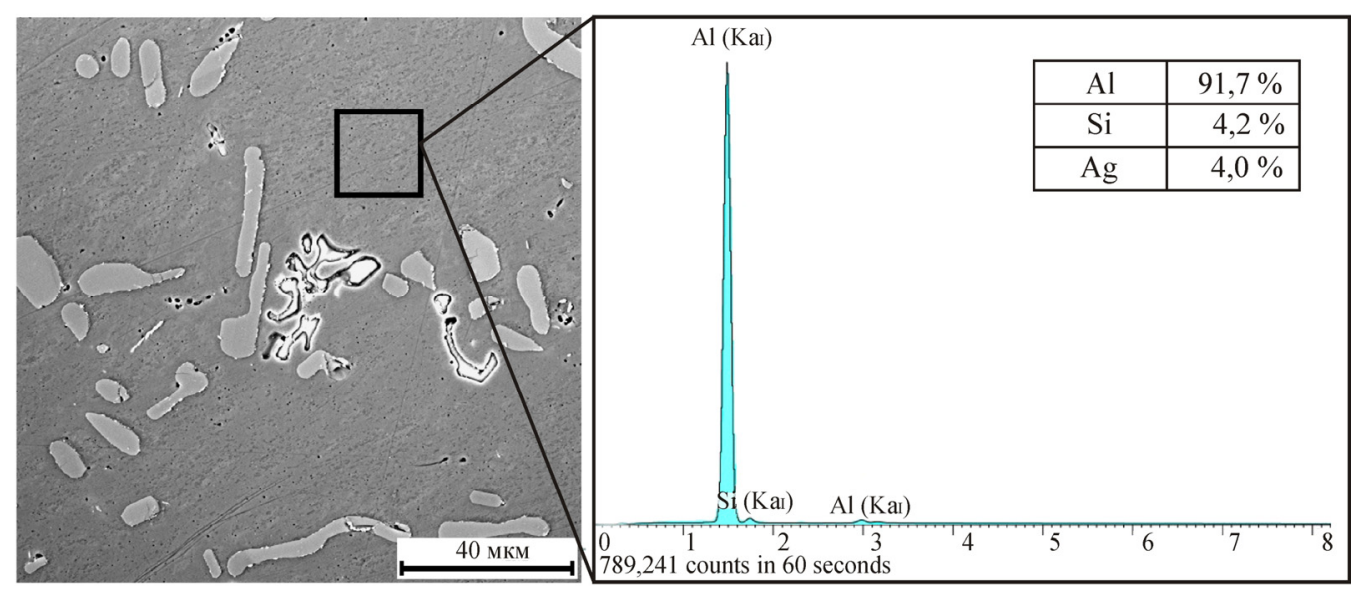

$a$

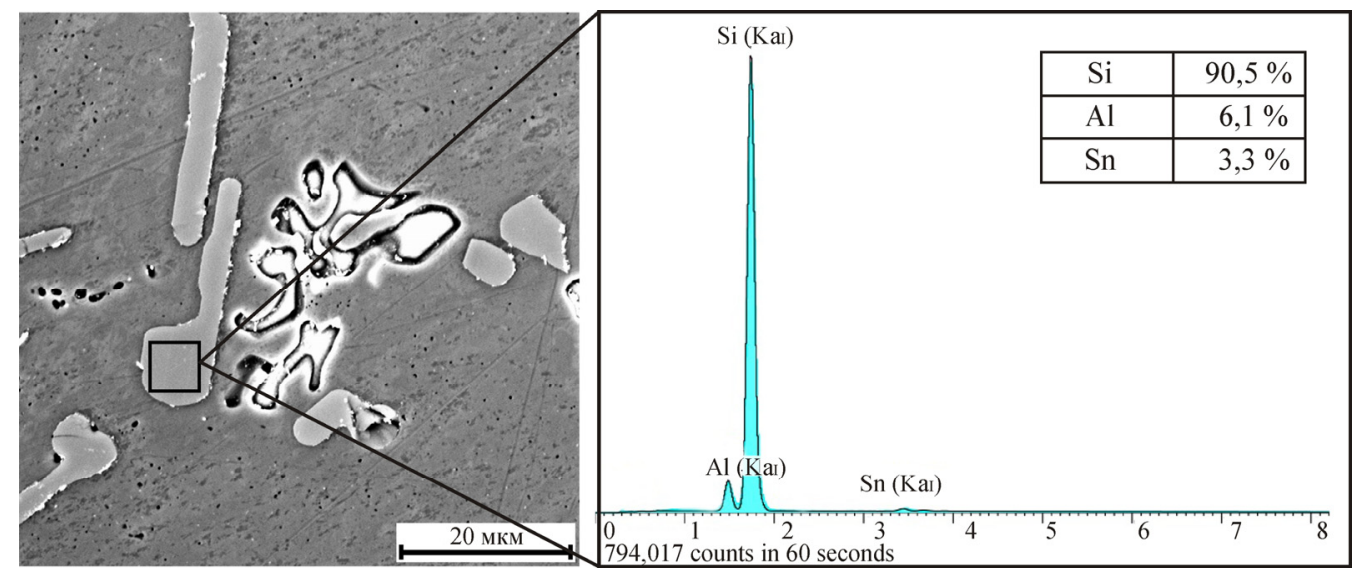

$\sigma$

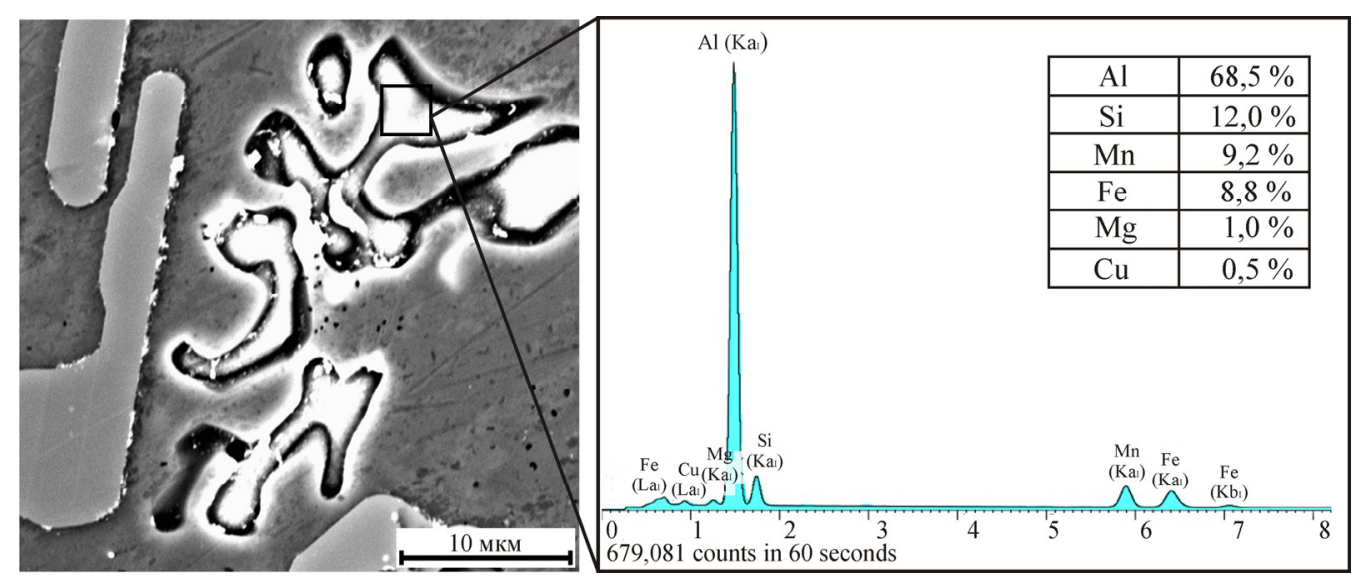

B

Рис. 1. Микростроение и элементный состав структур сплава АК9ч, полученный с помощью SEM: $a$ - элементный состав твердого раствора $\alpha$-фазы алюминия; $\sigma$ - элементный состав иглоподобного структурного элемента; 8 - элементный состав иероглифоподобной эвтектики 


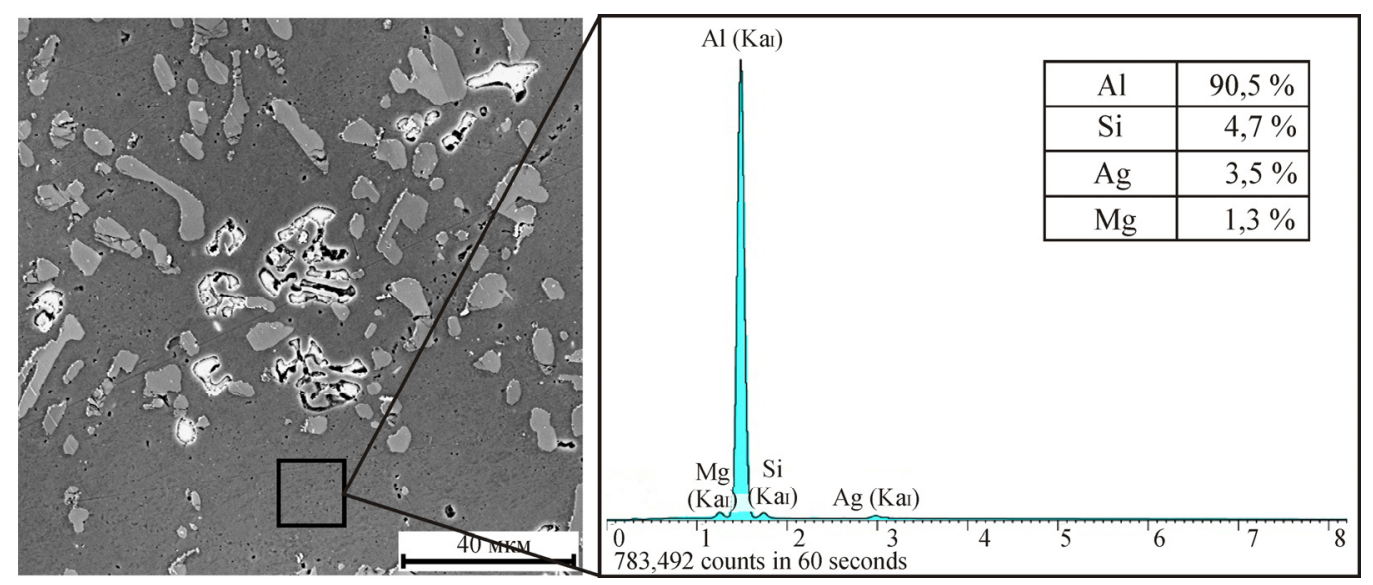

a

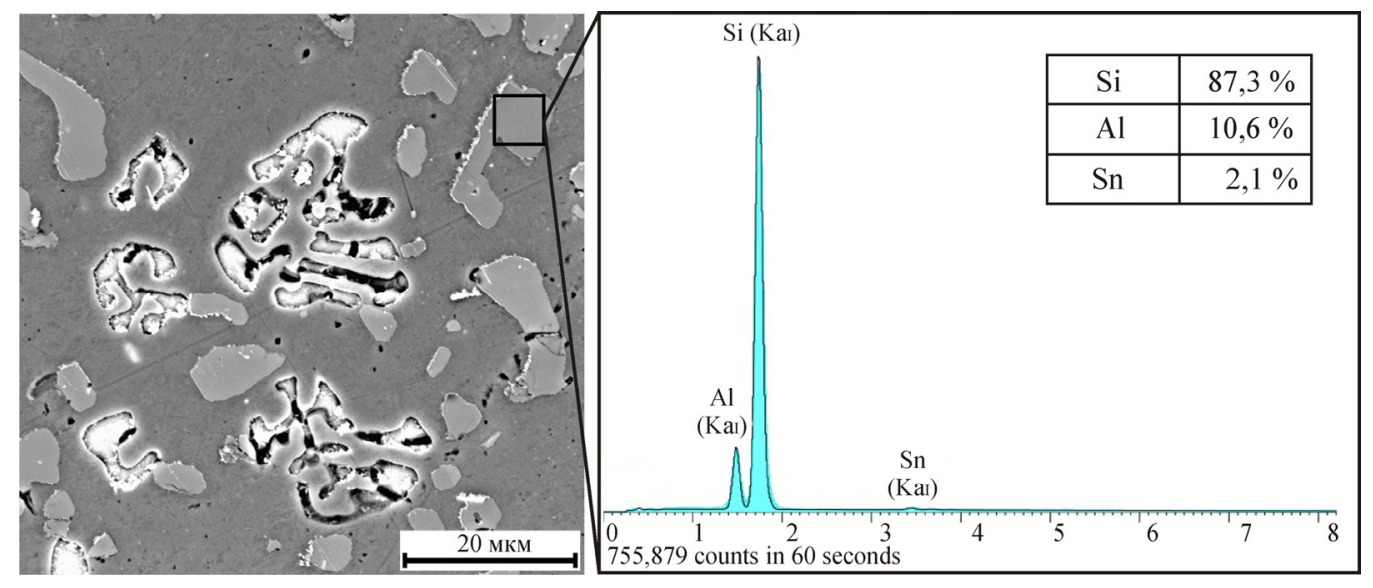

$\sigma$

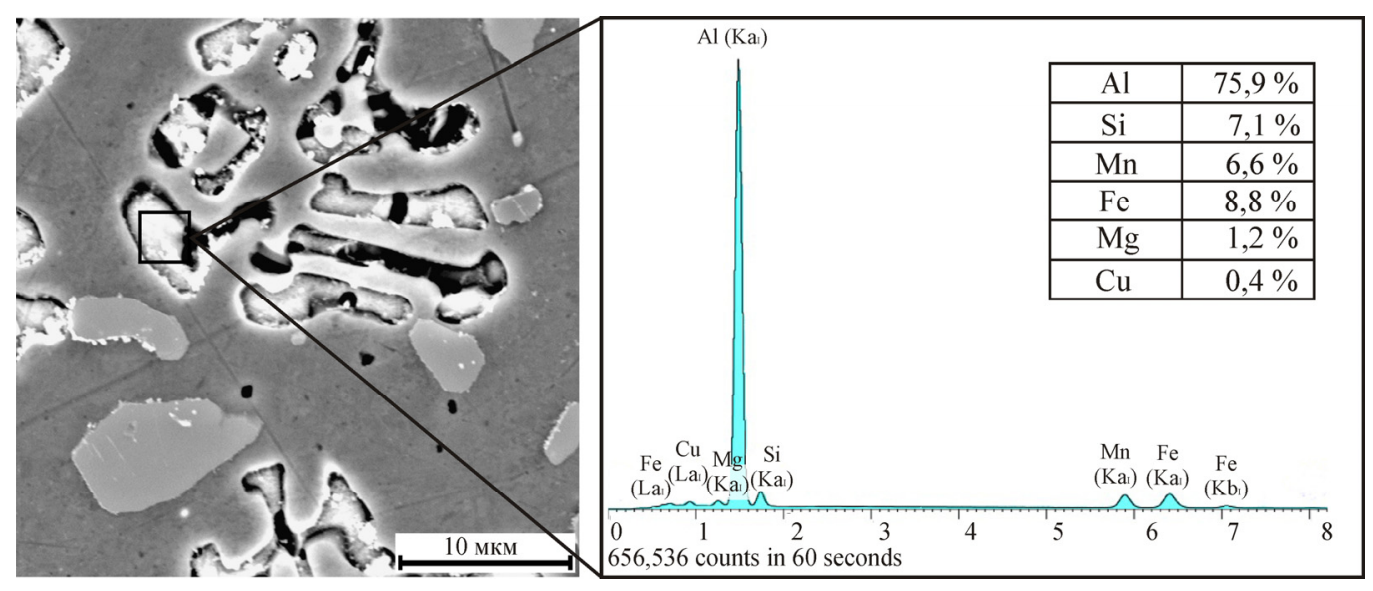

B

Рис. 2. Элементный состав структур сплава АК9чМ*, полученный с помощью SEM:

$a$ - элементный состав твердого раствора $\alpha$-фазы алюминия; $\sigma$ - элементный состав иглоподобного структурного элемента; в - элементный состав иероглифоподобной эвтектики

В табл. 2 и 3 представлены все результаты элементного анализа твердого раствора $\alpha$-фазы алюминия и всех остальных фаз сплавов АК9ч и АК9чМ*. Результаты энергодисперсионного спектрального анализа свидетельствуют об отсутствии кислорода в связанном состоянии или в виде окисных пленок. 
Химический состав фаз и структурных составляющих в сплаве АК9ч

\begin{tabular}{|c|c|c|c|c|c|c|c|c|c|c|}
\hline \multirow{3}{*}{$\begin{array}{c}\text { Номер } \\
\text { поля сбора }\end{array}$} & \multicolumn{10}{|c|}{ Содержание элементов, мас.\% } \\
\hline & \multicolumn{10}{|c|}{ Матричный материал (основа) } \\
\hline & $\mathrm{Al}$ & $\mathrm{O}$ & $\mathrm{Ag}$ & $\mathrm{Cu}$ & $\mathrm{Mg}$ & $\mathrm{Si}$ & $\mathrm{Fe}$ & $\mathrm{Mn}$ & $\mathrm{Zr}$ & $\mathrm{Sn}$ \\
\hline 1 & 91,7 & - & 4 & - & - & 4,2 & - & - & - & - \\
\hline 4 & 92 & - & 4 & - & - & 4 & - & - & - & - \\
\hline 11 & 89,8 & - & 3,8 & - & 1,7 & 4,6 & - & - & - & - \\
\hline 16 & 90,6 & - & 3,7 & - & 1,6 & 4,1 & - & - & - & - \\
\hline 20 & 90,5 & - & 3,9 & - & 1,6 & 3,9 & - & - & - & - \\
\hline среднее & 90,92 & - & 3,88 & - & 1,63 & 4,16 & - & - & - & - \\
\hline \multicolumn{11}{|c|}{ Игольчатые структурные компоненты } \\
\hline \begin{tabular}{|c|} 
Номер \\
поля сбора
\end{tabular} & $\mathrm{Al}$ & $\mathrm{O}$ & $\mathrm{Ag}$ & $\mathrm{Cu}$ & $\mathrm{Mg}$ & $\mathrm{Si}$ & $\mathrm{Fe}$ & $\mathrm{Mn}$ & $\mathrm{Zr}$ & Sn \\
\hline 2 & 6,1 & - & - & - & - & 90,5 & - & - & - & 3,3 \\
\hline 6 & 10,2 & - & - & - & - & 87 & - & - & - & 2,9 \\
\hline 10 & 8,8 & - & - & - & - & 88,3 & - & - & - & 2,9 \\
\hline 12 & 9,8 & - & - & - & - & 87,6 & - & - & - & 2,5 \\
\hline 18 & 6,5 & - & - & - & - & 89,9 & - & - & - & 3,5 \\
\hline среднее & 8,28 & - & - & - & - & 88,66 & - & - & - & 3,02 \\
\hline \multicolumn{11}{|c|}{ Иероглифоподобные структурные компоненты } \\
\hline $\begin{array}{c}\text { Номер поля } \\
\text { сбора }\end{array}$ & $\mathrm{Al}$ & $\mathrm{O}$ & $\mathrm{Ag}$ & $\mathrm{Cu}$ & $\mathrm{Mg}$ & $\mathrm{Si}$ & $\mathrm{Fe}$ & $\mathrm{Mn}$ & $\mathrm{Zr}$ & Sn \\
\hline 3 & 71,9 & - & - & 0,6 & 1 & 15,9 & 4,8 & 5,7 & - & - \\
\hline 4 & 68,5 & - & - & 0,5 & 1 & 12 & 8,8 & 9,2 & - & - \\
\hline 12 & 67,9 & - & - & 0,5 & 0,9 & 13,1 & 9,2 & 8,5 & - & - \\
\hline 16 & 66,8 & - & - & 0,5 & 0,9 & 14,4 & 8,8 & 8,6 & - & - \\
\hline 19 & 65,7 & - & - & 0,7 & 1,1 & 15,3 & 8,6 & 8,6 & - & - \\
\hline среднее & 70,1 & - & - & 0,56 & 1,1 & 12,22 & 7,94 & 8,1 & - & - \\
\hline
\end{tabular}

Таблица 3

Химический состав фаз и структурных составляющих в сплаве АК9ч $\mathrm{M}^{*}$

\begin{tabular}{|c|c|c|c|c|c|c|c|c|c|c|}
\hline \multicolumn{10}{|c|}{ Матричный материал (основа) } \\
\hline $\begin{array}{c}\text { Номер поля } \\
\text { сбора }\end{array}$ & $\mathrm{Al}$ & $\mathrm{O}$ & $\mathrm{Ag}$ & $\mathrm{Cu}$ & $\mathrm{Mg}$ & $\mathrm{Si}$ & $\mathrm{Fe}$ & $\mathrm{Mn}$ & $\mathrm{Zr}$ & $\mathrm{Sn}$ \\
\hline 2 & 89,3 & - & 3,2 & - & 1,3 & 6,2 & - & - & - & - \\
\hline 9 & 90,5 & - & 3,5 & - & 1,3 & 4,7 & - & - & - & - \\
\hline 10 & 91,4 & - & 3,0 & - & - & 5,6 & - & - & - & - \\
\hline 14 & 91,2 & - & 3,3 & - & - & 5,5 & - & - & - & - \\
\hline 16 & 89,6 & - & 3,6 & - & 1,4 & 5,4 & - & - & - & - \\
\hline среднее & 91,66 & - & 3,43 & - & 1,33 & 5,48 & - & - & - & - \\
\hline \multicolumn{8}{|c|}{ Игольчатые структурные компоненты } & & & \\
\hline $\begin{array}{c}\text { Номер поля } \\
\text { сбора }\end{array}$ & $\mathrm{Al}$ & О & \multicolumn{10}{|c|}{ Аg } & Си & $\mathrm{Mg}$ & $\mathrm{Si}$ & $\mathrm{Fe}$ & $\mathrm{Mn}$ & $\mathrm{Zr}$ & $\mathrm{Sn}$ \\
\hline 8 & 10,6 & - & - & - & - & 87,3 & - & - & - & 2,1 \\
\hline
\end{tabular}


Окончание табл. 3

\begin{tabular}{|c|c|c|c|c|c|c|c|c|c|c|}
\hline \multicolumn{11}{|c|}{ Матричный материал (основа) } \\
\hline \begin{tabular}{|c|} 
Номер поля \\
сбора
\end{tabular} & $\mathrm{Al}$ & $\mathrm{O}$ & $\mathrm{Ag}$ & $\mathrm{Cu}$ & $\mathrm{Mg}$ & $\mathrm{Si}$ & $\mathrm{Fe}$ & $\mathrm{Mn}$ & $\mathrm{Zr}$ & $\mathrm{Sn}$ \\
\hline 12 & 19,2 & - & - & - & - & 79,5 & - & - & - & 1,2 \\
\hline 16 & 9,4 & - & - & - & - & 88,4 & - & - & - & 2,2 \\
\hline 19 & 9,1 & - & - & - & - & 88,6 & - & - & - & 2,0 \\
\hline 20 & 10,0 & - & - & - & - & 87,5 & - & - & - & 2,5 \\
\hline среднее & 11,66 & - & - & - & - & 87,1 & - & - & - & 1,93 \\
\hline \multicolumn{11}{|c|}{ Иероглифоподобные структурные компоненты } \\
\hline $\begin{array}{c}\text { Номер поля } \\
\text { сбора }\end{array}$ & $\mathrm{Al}$ & $\mathrm{O}$ & $\mathrm{N}$ & $\mathrm{Cu}$ & $\mathrm{Mg}$ & $\mathrm{Si}$ & $\mathrm{Fe}$ & $\mathrm{Mn}$ & $\mathrm{Zr}$ & $\mathrm{Sn}$ \\
\hline 1 & 64,4 & - & - & 1,3 & 0,6 & 14,3 & 8 & 8,1 & - & - \\
\hline 4 & 75,9 & - & - & 0,4 & 1,2 & 7,1 & 8,8 & 6,6 & - & - \\
\hline 6 & 70,7 & - & - & 0,3 & - & 11,8 & 8,8 & 8,4 & - & - \\
\hline 12 & 70,0 & - & - & 0,4 & 0,9 & 12,0 & 8,3 & 8,3 & - & - \\
\hline 20 & 70,4 & - & - & - & 0,9 & 14,0 & 8,7 & 6,0 & - & - \\
\hline среднее & 70,28 & 0 & 0 & 0,6 & 0,9 & 11,84 & 8,52 & 7,48 & - & - \\
\hline \multicolumn{11}{|c|}{ Структурный компонент (белый стержень и белая окантовка) } \\
\hline \begin{tabular}{|c|} 
Номер поля \\
сбора
\end{tabular} & $\mathrm{Al}$ & $\mathrm{O}$ & $\mathrm{Ag}$ & $\mathrm{Cu}$ & $\mathrm{Mg}$ & $\mathrm{Si}$ & $\mathrm{Fe}$ & $\mathrm{Mn}$ & $\mathrm{Zr}$ & $\mathrm{Sn}$ \\
\hline 2 & 40 & - & - & 1 & 1 & 25,9 & - & - & 32,1 & - \\
\hline 8 & 17,6 & - & - & - & - & 52,7 & - & - & 29,8 & - \\
\hline 12 & 49,8 & - & - & 1,8 & - & 23,6 & - & - & 24,1 & - \\
\hline 16 & 51,1 & - & - & 1,8 & 1,1 & 20,6 & - & - & 25,4 & - \\
\hline 18 & 36,8 & - & - & 2,4 & 0,8 & 25,5 & - & - & 34,5 & - \\
\hline
\end{tabular}

Помимо традиционных структурных составляющих для сплавов АК9ч и АК9чМ“ металлографический анализ показал наличие частиц, расположенных по границам структурных элементов (показаны стрелками на рис. 3), а также светлых стержней или пластин. Светлые пластины расположены хаотично по всему объему расплава. Наличие пластин характерно как для сплава АК9ч, так и для сплава после модифицирования - АК9ч М*.
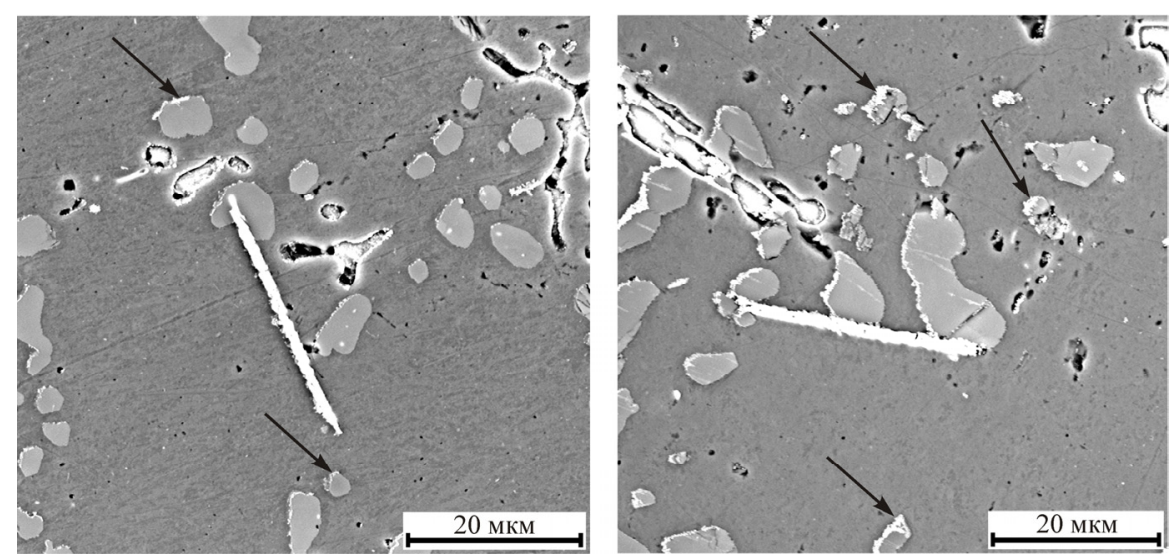

Рис. 3. Светлые частицы. Получено с помощью $\mathrm{SEM} \times 4000$ 
Анализ особенностей поверхности разрушения в виде свободно кристаллизующихся объемов в мезои макропорах и полостях также выявил компоненты в виде светлых частиц (показаны стрелками на рис. 4). Полученные результаты хорошо согласуются со структурными особенностями, описанными ранее.

Стоит отметить, что в сплаве АК9ч частицы расположены хаотичными группами, в то время как в сплаве АК9ч $\mathrm{M}^{*}$ подобные частицы расположены более равномерно. За счет этого, по мнению авторов настоящей работы, в данном сплаве на поверхностях свободно кристаллизующегося сплава АК9ч $\mathrm{M}^{*}$ реализуется выраженный ступенчатый микрорельеф. Важной особенностью, кроме того, является то, что выделившиеся частицы в сплаве АК9ч $\mathrm{M}^{*}$ гораздо мельче выделившихся частиц в сплаве АК9ч. Наличие ступенчатой формы свободно кристаллизующихся объемов в сплаве АК9ч $\mathrm{M}^{*}$ свидетельствует о более значительных возможностях сдерживания мигрирующей границы в процессе кристаллизации при введении модификаторов, которые, являясь поверхностно-активными веществами, сдерживают рост зерен, а также рост и коагуляцию светлых частиц, которые, распределяясь более равномерно в объеме расплава, приводят к общему диспергированию структуры. В связи с этим, по мнению авторов, важно исследовать элементный состав данных частиц.

Исследование элементного состава светлых час-

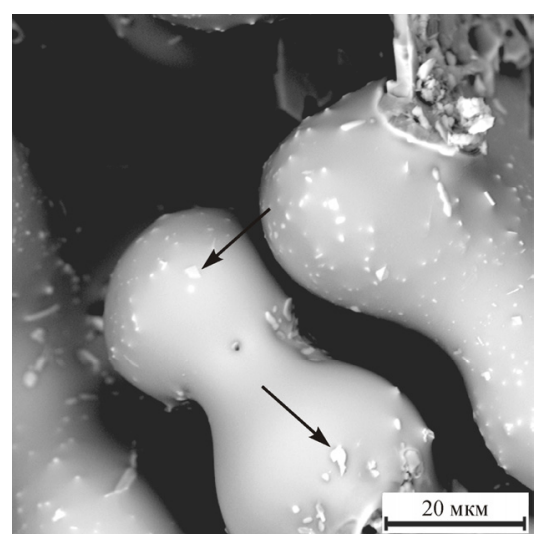

$a$

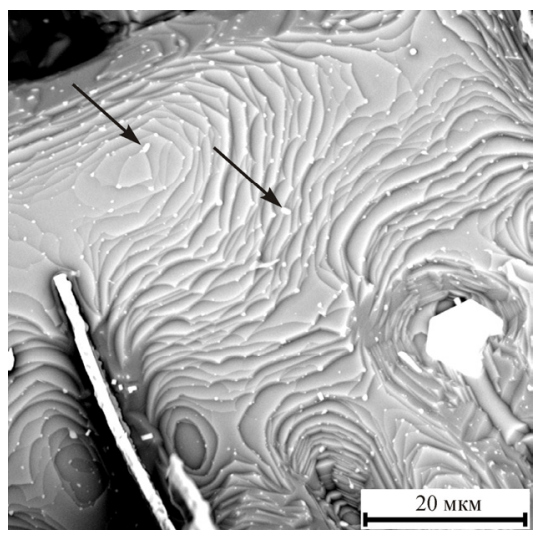

б

Рис. 4. Структурная особенность избыточного циркония (SEM): $a$ - в сплаве АК9ч $\times 3500 ; \sigma$ - в сплаве АК9ч $\mathrm{M}^{*} \times 4000$ тиц, выделившихся по границам структурных элементов, а также светлых пластин в сплавах АК9ч и АК9ч $\mathrm{M}^{*}$ с помощью энергодисперсионного спектрометра электронного микроскопа, показало, что в состав этих частиц и пластин входит цирконий со средним содержанием порядка $30 \%$ (рис. 5). Таким образом, можно сделать заключение о том, что в случае локального пересыщения $\alpha$-матрицы цирконием в микрообъемах структуры этот процесс приводит к выделению циркония в виде светлых пластин (см. рис. 4) [11-12].

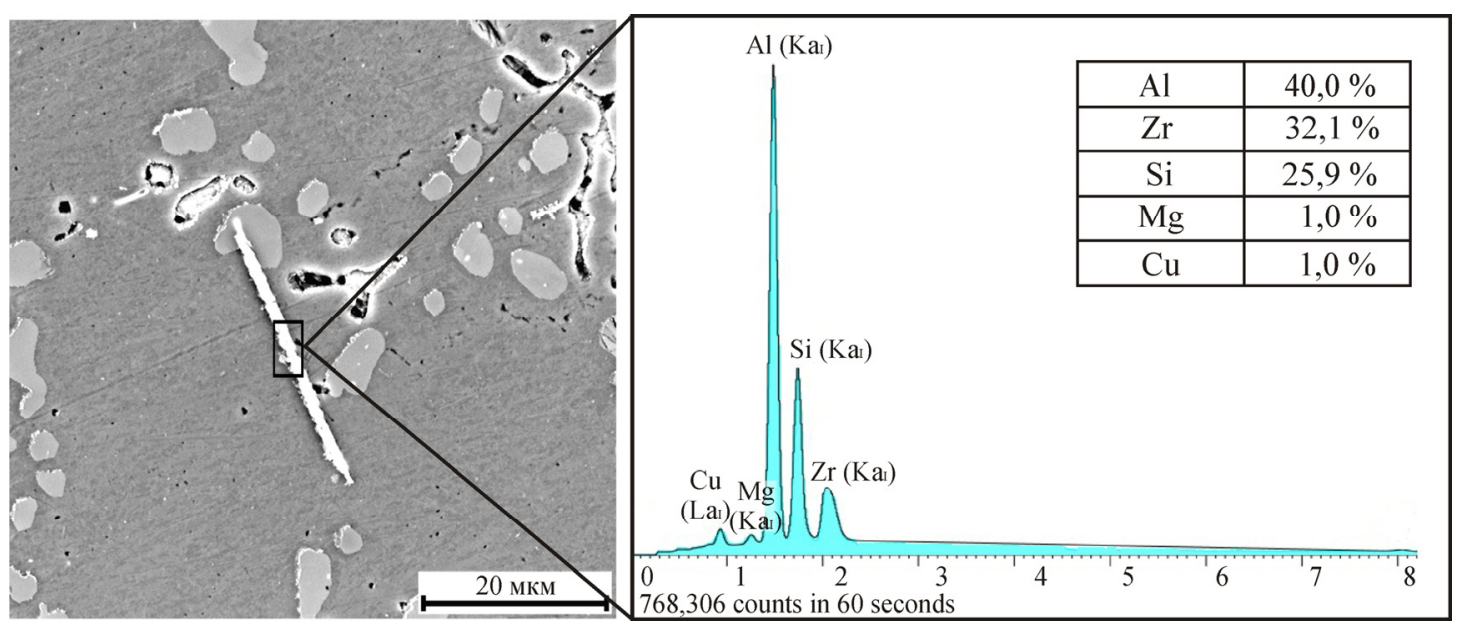

Рис. 5. Внешний вид и элементный состав циркониевой пластины (SEM) 
Стоит отметить, что в [13-15] отмечали наличие никеля, цинка и титана в отдельных структурных элементах. В данной работе авторам не удалось обнаружить цинк ( $\mathrm{Zn})$, никель $(\mathrm{Ni})$ и титан $(\mathrm{Ti})$ в компонентах структурных элементов при проведении энергодисперсионного элементного анализа состава сплавов АК9ч и АК9ч $\mathrm{M}^{*}$. Таким образом, можно предположить, что цинк и никель могут входить в состав алюминиевой матрицы в малых концентрациях.

\section{Выводы}

1. Структура гомогенизированных сплавов АК9ч и АК9чМ* включает $\alpha$-матрицу (Al), двойную эвтектику $(\mathrm{Al}-\mathrm{Si})$, четверную эвтектику $\left(\mathrm{Al}_{15}(\mathrm{Fe}, \mathrm{Mn})_{3} \mathrm{Si}_{2}\right)$ и частицы циркония. Помимо алюминия в элементный состав матрицы входят кремний и серебро. В состав двойной эвтектики входит олово, а в составе четверной эвтектики обнаружено наличие магния и меди.

2. Частицы циркония располагаются по границам зерен четверной эвтектики и $\beta$-фазы кремния в двойной эвтектике, а обнаруженные пластины первичного циркония вырастают из областей границ $\beta$-фазы кремния или близким к ним областям.

3. Ступенчатый вид свободно кристаллизующихся объемов, обнаруженных в сплаве АК9ч $\mathrm{M}^{*}$, указывает на сдерживание роста зерен при введении модификатора в сплав. Также установлено, что в модифицированном сплаве АК9ч $\mathrm{M}^{*}$ распределение частиц циркония происходит более равномерно в объеме расплава, по сравнению со сплавом АК9ч. Показано, что в сплаве АК9чМ ${ }^{*}$ количество частиц циркония больше и они более дисперсные по сравнению с циркониевыми частицами в сплаве АК9ч. Этот факт еще раз подтверждает положительное влияние совместной гомогенизации с последующим модифицированием сплава.

\section{Библиографический список}

1. Лахтин Ю.М., Леонтьева В.П. Материаловедение: учебник для высш. техн. учеб. заведений. 3-е изд. - М.: Машиностроение, 1990. - 528 с.

2. Смирягин А.П., Смирягина Н.А., Белова А.В. Промышленные цветные металлы и сплавы. 3-е изд. - М.: Металлургия, 1974. - 488 с.

3. Алюминиевые сплавы. Плавка и литье алюминиевых сплавов: справ. / под ред. Добаткина. М.: Металлургия, 1983. -351 с.

4. Цветное литье: справ. / Н.М. Галдин, Д.Ф. Чернега, Д.Ф. Иванчук [и др.]. - М.: Машиностроение, $1989 .-529$ с.

5. Мальцев М.В. Металлография промышленных цветных металлов и сплавов. - М.: Металлургия, 1970. - 368 с. M., 1955.

6. Мальцев М.В. Модифицирование структуры металлических сплавов // Алюминиевые сплавы. -

7. Комплексное модифицирование вторичных силуминов / А.А. Митяев, И.П. Волчок, Р.А. Фролов, К.Н. Лоза, О.В. Гнатенко, В.В. Лукинов // Вестн. Днепропетр. нац. ун-та железнодорож. транспорта. 2010. - Вып. № 34. - С. 87-96.

8. Мондольфо Л.Ф. Структура и свойства алюминиевых сплавов: моногр.: пер. с англ. - М.: Металлургия, 1979. - $640 \mathrm{c}$.

9. Мальцев М.В. Металлография промышленных цветных металлов и сплавов. - М.: Металлургия, 1970. $-368 \mathrm{c}$.

10. Белов Н.А., Савченко С.В., Хван А.В. Фазовый состав и структура силуминов: справ. - М.: Изд-во МИСиС, 2007. - 283 с.

11. Шреибер Г.К., Перлин С.М., Шибряен Б.Ф. Конструкционные материалы в нефтяной, нефтехимической и газовой промышленности: справ. - 2-е изд. - М.: Машиностроение, 1909. - 396 с.

12. Напалков В.И. Легирование и модифицирование алюминия и магния. - М.: Изд-во МИСиС, 2002. $-376 \mathrm{c}$.

13. ГОСТ 1583-93. Сплавы алюминиевые литейные. - М., 1993.

14. Золоторевский В.С., Белов Н.А. Металловедение литейных алюминиевых сплавов. - М.: Издво МИСиС, 2005. - 376 с. 
15. Попова М.В., Кибко Н.В. Прогрессивные способы повышения свойств алюминиевых сплавов: учеб. пособие / Сиб. гос. индустр. ун-т. - Новокузнецк, 2012. - 153 с.

\section{References}

1. Lakhtin Yu. M., Leonteva V. P. Materialovedenie: Uchebnik dlya vysshikh tekhnicheskikh uchebnykh zavedeniy. 3-e izd. [Material Science: A Textbook for Higher Technical Institutions. $3^{\text {rd }}$ edition]. Moscow.: Mashinostroenie, 1990, 528 p.

2. Smiryagin A. P., Smiryagina N. A., Belova A. V. Promyshlennye tsvetnye metally i splavy - 3-e izd. [Industrial non-ferrous metals and alloys. $3^{\text {rd }}$ edition]. Moscow.: Metallurgiya, 1974, 488p.

3. M.B. Altman, A.D. Andreev, N.N. Belousov. Alyuminievye splavy. Plavka i lite alyuminievykh splavov. Spravochnik [Aluminum alloys. Melting and casting of aluminum alloys. Directory]. Moscow.: Metallurgiya, 1983, $351 \mathrm{p}$.

4. Galdin N.M., Chernega D.F., Ivanchuk D.F. Tsvetnoe lite: Spravochnik [Non-ferrous metals casting: Directory]. Moscow.: Mashinostroenie, 1989, 529 p.

5. Maltsev, M. V. Metallografiya promyshlennykh tsvetnykh metallov i splavov [Metallography of industrial non-ferrous metals and alloys]. Moscow.: Metallurgiya, 1970, 368 p.

6. Maltsev M. V. Modifitsirovanie struktury metallicheskikh splavov, v sb.: Alyuminievye splavy [Modification of the structure of metal alloys, in the collection: Aluminum alloys]. Moscow, 1955.

7. Mityaev A. A., Volchok I. P., Frolov R. A., Loza K. N., Gnatenko O. V., Lukinov V. V. Kompleksnoe modifitsirovanie vtorichnykh siluminov [Complex modification of secondary silumines]. Nauka i progress transporta. Vestnik Dnepropetrovskogo natsionalnogo universiteta zheleznodorozhnogo transporta, 2010, no. 34/2010, pp. 87-96.

8. Mondolfo, L. F. Struktura i svoystva alyuminievykh splavov: monografiya; per. s angl. [Structure and properties of aluminum alloys: monograph; translated from English]. Moscow: Metallurgiya, 1979, 640 p.

9. Maltsev, M. V. Metallografiya promyshlennykh tsvetnykh metallov i splavov [Metallography of industrial non-ferrous metals and alloys]. Moscow: Metallurgiya, 1970, 368 p.

10. Belov N.A., Savchenko S.V., Khvan A.V. Fazovyy sostav i struktura siluminov. Spravochnoe izdanie [Phase composition and structure of silumin. Reference edition]. Moscow: National University of Science and Technology, MiSiS, 2007, 283 p.

11. Shreiber G. K.. Perlin S. M., Shibryaen B. F. Konstruktsionnye materialy v neftyanoy, neftekhimicheskoy i gazovoy promyshlennosti. 2-oe izdanie. Spravochnoe izdanie [Structural materials in the oil, petrochemical and gas industries. 2nd edition. Reference edition]. Moscow: Mashinostroenie, 1909, 396 p.

12. Napalkov V.I. Legirovanie i modifitsirovanie alyuminiya i magniya [Doping and modification of aluminum and magnesium]. Moscow: National University of Science and Technology, MiSiS, 2002, 376 p.

13. GOST 1583-93. Splavy aliuminievye liteinye [Casting of aluminum alloys].

14. Zolotorevskiy V.S., Belov N.A. Metallovedenie liteynykh alyuminievykh splavov [Metallurgy of foundry aluminum alloys]. Moscow: National University of Science and Technology, MiSiS, 2005, 376 p.

15. Popova M.V., Kibko N.V. Progressivnye sposoby povysheniya svoystv alyuminievykh splavov. Uchebnoe posobie [Progressive ways to enhance the properties of aluminum alloys. Tutorial]. Sibirskii gosudarstvennyi industrialnyi universitet, Novokuznetsk, 2012, 153 p.

\section{Об авторах}

Долгополов Владимир Геннадьевич (Пермь, Россия) - аспирант кафедры «Металловедение, термическая и лазерная обработка металлов» Пермского национального исследовательского политехнического университета (614990, г. Пермь, Комсомольский пр., д. 29, e-mail: mto@pstu.ru).

Дубровский Владимир Александрович (Пермь, Россия) - кандидат технических наук, заместитель главного металлурга ПАО «Протон-ПМ» (614990, г. Пермь, Комсомольский пр., д. 93, e-mail: vdubrovskii@protonpm.ru).

Симонов Михаил Юрьевич (Пермь, Россия) - кандидат технических наук, младший научный сотрудник кафедры «Металловедение, термическая и лазерная обработка металлов» Пермского национального исследовательского политехнического университета (614990, г. Пермь, Комсомольский пр., д. 29 , e-mail: mto@pstu.ru).

Симонов Юрий Николаевич (Пермь, Россия) - доктор технических наук, профессор кафедры «Металловедение, термическая и лазерная обработка металлов» Пермского национального иссле- 
довательского политехнического университета (614990, г. Пермь, Комсомольский пр., д. 29, e-mail: mto@pstu.ru).

Медведева Мария Андреевна (Пермь, Россия) - магистрант кафедры «Металловедение, термическая и лазерная обработка металлов» Пермского национального исследовательского политехнического университета (614990, г. Пермь, Комсомольский пр., д. 29, e-mail: mto@ pstu.ru).

\section{About the authors}

Vladimir G. Dolgopolov (Perm, Russian Federation) - Postgraduate Student, Department of Metal Science, Thermal and 1Aser Treatment of Metals, Perm National Research Polytechnic University (29, Komsomolsky av., Perm, 614990, Russian Federation, e-mail: mto@pstu.ru).

Vladimir A. Dubrovskiy (Perm, Russian Federation) - Ph. D. of Technical Sciences, Deputy of the Chief Metallurgist, JSC «Proton-PM»(93, Komsomolsky av., Perm, 614990, Russian Federation, e-mail: vdubrovskii@protonpm.ru).

Mikhail Yu. Simonov (Perm, Russian Federation) - Ph. D. of Technical Sciences, Junior Research Assistant, Department of Metal Science, Thermal and Laser Treatment of Metals, Perm National Research Polytechnic University (29, Komsomolsky av., Perm, 614990, Russian Federation, e-mail: mto@ pstu.ru).

Yuriy N. Simonov (Perm, Russian Federation) - Doctor of Technical Sciences, Department of Metal Science, Thermal and Laser Treatment of Metals, Perm National Research Polytechnic University (29, Komsomolsky av., Perm, 614990, Russian Federation, e-mail: mto@pstu.ru).

Mariya A. Medvedeva (Perm, Russian Federation) - Master Student, Department of Metal Science, Thermal and Laser Treatment of Metals, Perm National Research Polytechnic University (29, Komsomolsky av., Perm, 614990, Russian Federation, e-mail: mto@pstu.ru).

Получено 08.09.2017 